\title{
DIREITO À SAÚDE: TRATAMENTO TERAPÊUTICO COM ANÁLOGOS DE INSULINA AOS PORTADORES DE DIABETES MELLITUS TIPO 1 E A JURISPRUDÊNCIA NACIONAL.
}

\author{
Rafael Mota de Queiroz ${ }^{1}$ \\ Caio Rodrigues Bena Lourenço ${ }^{2}$
}

\section{RESUMO}

$\mathrm{O}$ artigo afirma a fundamentalidade do direito à saúde como direito social, e o fazer assim traz uma abordagem interdisciplinar entre direito (a saúde) e o tratamento médico destinado aos portadores de diabetes mellitus tipo1. Por meio de revisão da literatura, e uma análise qualitativa analisa o direito a saúde na perspectiva dos portadores dessa doença, descreve a assistência a esses pacientes com a incorporação de novos medicamentos (análogos de insulina), e como a jurisprudência nacional se porta quanto ao fornecimento de medicamentos, em destaque o Supremo Tribunal Federal.

Palavras-chave: Direito a saúde; Diabetes tipo 1; Jurisprudência.

\section{RIGHT TO HEALTH: THERAPEUTIC TREATMENT WITH INSULIN ANALOGUES IN PATIENTS WITH TYPE 1 DIABETES MELLITUS AND BRAZILIAN JURISPRUDENCE.}

\begin{abstract}
The article affirms the fundamentality of the right to health as a social right, and doing that, brings an interdisciplinary approach between right (health) and medical treatment for patients with type 1 diabetes mellitus. Through a literature review, and qualitative analysis analyzes the right to health from the perspective of the patients, describes the assistance to these patients with the incorporation of new drugs (insulin analogues), and how the national jurisprudence behaves as to supply of medicines, highlighting the Federal Supreme Court.
\end{abstract}

Keywords: Right to health; type 1 Diabetes; Jurisprudence.

\footnotetext{
${ }^{1}$ Mestrando do Programa de Pós-Graduação em Direito Fundamentais (PPGDF) da Universidade da Amazônia (UNAMA), Especialista em Direito Público pela Universidade Anhanguera-Uniderp, especialista em Direito Penal e Processual Penal pela Universidade Estácio de Sá. Procurador Municipal em Belém/PA. Endereço eletrônico: rafaelqueirozadv@hotmail.com.

${ }^{2}$ Mestrando do Programa de Pós-Graduação em Direito Fundamentais (PPGDF) da Universidade da Amazônia (UNAMA), Bolsista do Programa de Suporte à Pós-Graduação de Instituições de Ensino Particulares da Coordenação de Aperfeiçoamento de Pessoal de Nível Superior (PROSUP/CAPES), modalidade taxista. Advogado com ampla atuação na área Penal, Ambiental e Minerário, Membro da Comissão de Assuntos Minerários da OAB-PA, especialista em Direito Ambiental. Atualmente é colaborador da Faculdade Uninassau Belém. Endereço eletrônico: caio_louro5@hotmail.com.
} 


\section{1 - INTRODUÇÃO}

De pautas morais ou à direitos positivos, muito já se avançou em relação a construção dos direitos humanos fundamentais, sendo o desafio atual a sua efetividade, ou eficácia social como esclarece Sarlet e Figueiredo (2010, p. 13).

Quanto a efetivação dos direitos fundamentais, chama atenção os que demandam, quase sempre, por parte do Estado, uma obrigação de natureza prestacional, aqui incluídos os direitos sociais, sobretudo em virtude da limitação de recursos.

Parte-se aqui do pressuposto de que determinados direitos (econômicos, sociais e culturais), ganharam suficiente fundamentalidade na Constituição Cidadã, e, a partir da nova ordem jurídica por ela implantada, se constituem como verdadeiros direitos.

Dado o recorte da presente análise, afirma-se a suficiente fundamentalidade do direito à saúde, sobretudo sob o ordenamento instaurado a partir da Constituição Federal de 1988 (artigos 6, e 196 a 200, v.g), e, sob sua égide, com a adoção de inúmeros instrumentos legislativos, destacando-se daí, em especial, a Lei $\mathrm{n}^{\circ}$ 8.080, de 19 de setembro de 1990, que dispõe sobre as condições para a promoção, proteção e recuperação da saúde, a organização e o funcionamento dos serviços correspondentes, e de outras providências.

$\mathrm{O}$ artigo centra-se, portanto, no direito à saúde, entendido como direito fundamental social, com suficiente normatividade, todavia, sujeito a eficácia social, sobretudo em um pais considerado ainda em desenvolvimento, conforme Bresser-Pereira (2016), e, que, por isso, enfrenta uma série de desafios, e a necessidade de cumprir com os objetivos definidos pela Carta Política (art. $3^{\circ}$ ), e diante de uma sociedade ávida e necessitada de ações estatais capazes de dar concretude e atendimento as suas legítimas aspirações, diga-se, não somente quanto à liberdade, segurança, e participação, mas a serviços e bens mínimos capazes de garantir vida digna.

Nesta lógica, quanto ao direito à saúde, nos propomos a analisar, de modo mais particular, o acesso terapêutico de pacientes portadores de diabetes mellitus (ou melito) tipo1, também aqui chamado de DM 1, ao Sistema Único de Saúde - SUS - não em relação ao tratamento clínico em si da doença, e o fornecimento da insulina e insumos ao tratamento contínuo no âmbito do sistema de saúde pública do SUS, que tem sido relativamente satisfatório, sobretudo, porquanto incorporado a Relação Nacional de Medicamentos Essenciais - RENAME (BRASIL, 2018), mas ao tratamento terapêutico atualmente 
incrementado pela adoção do uso de análogos de insulina, considerando seus efeitos à parcela dos portadores da doença, a necessidade das avaliações, e adoção dos critérios técnicos em relação a incorporação dessa nova tecnológicas em saúde, em particular as definições e competências definidas pela Lei $n^{\circ} 12.401 / 2011$, que alterou significativamente a Lei $n^{\circ}$ 8.080/1990, e criou, no âmbito do Ministério da Saúde, órgão de assessoramento, a Comissão Nacional de Incorporação de Tecnologias no SUS - CONITEC.

A temática acaba fluindo para a arena do Poder Judiciário, uma vez que, ao dizer respeito ao acesso à nova forma de tratamento terapêutico, e a qualidade de vida (pacientes de DM 1), o descompasso entre a política pública estatal para a implementação de novos tratamentos, e a negativa à tutela efetiva ao direito acaba desembocando e exigindo a intervenção judicial para o controle da inexistente ou insuficiente atuação estatal.

Estabelecidas tais premissas, o artigo, por meio de revisão da literatura, objetiva estabelecer uma análise interdisciplinar (direito e medicina), focando na fundamentalidade do direito social a saúde, na caracterização e tratamento digno aos portadores de diabetes mellitus tipo 1, com a incorporação de novos fármacos (análogos de insulina), fazendo, ao mesmo tempo, análise documental qualitativa da jurisprudência nacional quanto ao fornecimento de medicamentos pelo SUS, e recente decisão do Supremo Tribunal Federal suspendendo a obrigação de fornecimento desses análogos de insulina na rede pública (Suspensão de Tutela Provisória - STP $n^{\circ} 101$ ), e seus desdobramentos quanto a incorporação na rede básica das aludidas substâncias medicamentosas.

\section{2 - DIREITO À SAÚDE COMO DIREITO FUNDAMENTAL SOCIAL}

A Constituição Federal de 1988 foi o primeiro texto em nossa história constitucional a reconhecer o direito à saúde como direito fundamental (MENDES; BRANCO, 2015, p. 660).

É valido aqui estabelecer um conceito de saúde. O preâmbulo da Constituição da Organização Mundial de Saúde afirma que: "A saúde é um estado de completo bem-estar físico, mental e social, e não consiste apenas na ausência de doença ou de enfermidade" (OMS, 1946)

O desafio que se coloca aos direitos fundamentais de caráter social, como o direito a saúde, conforme adiante já se adiantou, é sempre o de sua efetividade social, "a materialização, no mundo dos fatos, dos preceitos legais e simboliza a aproximação, tão 
íntima quanto possível, entre o dever-ser normativo e o ser da realidade social" (BARROSO, 2009, p. 220).

Os direitos fundamentais se apresentam tanto em sua dimensão subjetiva, isto é, “(...) investem os seus beneficiários em situações jurídicas imediatamente desfrutáveis, a serem efetivadas por prestações positivas ou negativas, exigíveis ao Estado ou de outro eventual destinatário da norma" (BARROSO, 2009, p. 222).

Particularmente, ao direito a saúde, nos parece que a norma constitucional (art. 196) possui todos os elementos para tanto, pois há um dever jurídico, que pode ser violado, e uma vez violado, nasce ao seu titular uma pretensão, podendo se valer dos meios coercitivos, como de uma ação judicial (BARROSO, 2009, p. 221 a 222). A este respeito, por exemplo, aponta GOUVÊA (apud: FERNANDES, 2017, p. 729) que a partir da década de 1990, se tornou cada vez mais frequente o ajuizamento de ações perante o Poder Judiciário invocando o direito ao recebimento de medicamentos por parte do Poder Público.

Por outro lado, e de modo paralelo, numa relação de remissão e de complemento recíproco, há uma dimensão objetiva na qual os direitos fundamentais são considerados princípios básicos da ordem constitucional (MENDES; BRANCO, 2015, p. 168). Neste sentido, segundo Mendes e Branco (2015, p. 167):

Os direitos fundamentais transcendem a perspectiva da garantia de posições individuais, para alcançar a estatura de normas que filtram os valores básicos da sociedade política, expandindo-os para todo o direito positivo (...). Essa dimensão objetiva produz consequenciais apreciáveis. Ela faz com que o direito fundamental não seja considerado exclusivamente sob a perspectiva individualista, mas, igualmente que o bem por ela tutelado seja visto como um valor em si, a ser preservado e fomentado.

Como consequência da dimensão objetiva dos direitos fundamentais há o dever de proteção pelo Estado dos direitos fundamentais contra agressões do próprio Estado, de terceiros, ou de outros Estado. O Estado deve, portanto, adotar medidas que protejam efetivamente os direitos fundamentais, veda-se, neste sentido, não apenas o excesso, mas uma proteção insuficiente (CANARIS apud: MENDES; BRANCO, 2015, p. 631).

Dessa dimensão objetiva, associada ao dever estatal de proteção (defesa), surge um direito a prestação (MENDES; BRANCO, 2015, p. 167; e BONAVIDES, 2019, p. 680). Todavia, esse direito a prestação há de se conformar à liberdade de atuação dos órgãos públicos (discricionariedade) e ao condicionamento da reserva do possível. 
De outro lado, a doutrina aponta relacionado a essa dimensão objetiva, a perspectiva dos direitos à organização e ao procedimento (ALEXY, 2015, p 470 e ss; MENDES; BRANCO, 2015, p. 631; SOUZA NETO; SARMENTO, 2016, p. 378). Segundo essa classificação, existiriam direitos fundamentais que dependeriam, na sua concretização, de providências estatais com vistas à criação e conformação de órgãos e procedimentos imprescindíveis à sua efetivação (MENDES; BRANCO, 2015, p. 631)

Os direitos fundamentais sociais se encaixam, também nesta dimensão objetiva, seja em sua perspectiva de proteção, seja quanto ao direito à organização e procedimentos, o que pressupõe, em ambos os casos, que sejam atendidas condições fáticas-materiais para a sua realização.

Ora, o direito a saúde previsto no texto constitucional apresenta-se tanto em sua dimensão subjetiva, como objetiva, possuindo fundamentalidade suficiente, e qualquer entendimento em o qualificar como norma programática ou limitativa de sua eficácia, faria tábua rasa de suas características aqui identificadas, e dos comandos dos $\S \S 1^{\circ}$ e $2^{\circ}$ do art. $5^{\circ}$, da Carta Política de 1998, que definem a aplicação imediata das normas definidoras de direitos e garantias fundamentais, e que os direitos e garantias expressos na Constituição não excluem outros decorrentes do regime e dos princípios por ela adotados, isto é, existem direitos fundamentais localizados topograficamente ao longo do texto constitucional, e que são de imediata aplicação.

\section{3 - DIABETES MELLITUS TIPO 1: TRATAMENTO E ANÁLOGOS DE INSULINA}

O diabetes mellitus é uma doença crônica, não transmissível, de importante morbimortalidade, e que vem tendo sua incidência aumentando ao longo dos últimos anos. Patologia caracterizada pelo aumento da glicemia no sangue, tem sua etiologia pela resistência à insulina, ou pela deficiência acentuada de insulina (ADA, 2018; IDF; 2017; OMS, 2016; SBD, 2017).

O diabetes pode ser classificado de acordo com sua etiologia, quando ocorre pela resistência à insulina é denominado de diabetes mellitus tipo 2 (DM2), e, pela insuficiência insulínica, dá-se o nome de diabetes mellitus tipo 1 (DM 1). O DM2 corresponde por cerca de 95\% dos casos e o DM 1 por 5\% (ADA, 2018; SBD, 2017). 
O diabetes mellitus tipo 1 é uma doença rara (IDF, 2017), como visto, corresponde a cerca de $5 \%$ dentre os portadores de diabetes, mas de importante morbimortalidade para aqueles dela acometidos (SBD, 2017).

A DM 1 ocorre devido a deficiência insulínica, em geral devido a autoimunidade, e seu tratamento consiste em insulinoterapia e modificação do estilo de vida (ADA, 2018). A insulina é o hormônio responsável pela entrada de glicose para as células do corpo, sua falta pode levar a complicações agudas com risco de vida como cetoacidose diabética, e crônicas como: retinopatia, nefropatia e doenças cardiovasculares (MELMED, 2016; BRASIL, 2018).

Dado a insuficiência da insulina nos pacientes com DM 1, e da importância clínica do controle glicêmico nesses pacientes, avanços na terapia insulínica vem sendo estudados ao longo dos anos em busca de um controle da doença com menores efeitos colaterais (SBD, 2017), isto é, a fim de dar ao paciente melhor qualidade de vida, ou de lidar com a doença.

Dentre os efeitos colaterais mais deletérios da insulinoterapia, tem-se a hipoglicemia. Definida como glicemia plasmática menor que $70 \mathrm{mg} / \mathrm{dl}$, isto significa a baixa presença de glicose no sangue, o que se manifesta clinicamente desde sudorese, taquicardia, até com eventos mais graves como convulsões, perda de consciência e óbito (VILAR, 2016).

Para um controle ideal com metas adequadas e com menor incidência de hipoglicemias o usuário é beneficiado pela automonitorização glicêmica (glicemia capilar) que é realizada através de aparelhos, lancetas e fitas que são de custos altos para os pacientes. Sem a automonitorização, o paciente não tem como saber como está sua glicemia ao longo do dia, ou a razão de eventual mal-estar, o que aumenta o custo do tratamento para os pacientes, e os expõe a maior risco de hipoglicemias graves.

A terapia do DM 1 disponibilizada pelo SUS consiste em insulina NPH (Neutral Protamine Hagedorn) e insulina regular, sendo ainda fornecido seringas com agulha acoplada para aplicação (BRASIL, 2018).

Embora o acesso gratuito a essa terapia e insumo se constitua como progresso no âmbito da rede pública, muitas vezes ela não possibilita o alcance de metas glicêmicas pelos pacientes devido a sua farmacodinâmica estar associada a picos de ação insulínica e menor estabilidade da insulina no corpo, o que ocasionam hipoglicemias (SBD, 2017).

No mesmo sentido, é o último Protocolo Clínico e Diretrizes Terapêuticas da Diabete Melito 1, da CONITEC, aprovado pela Portaria Conjunta no 08, da Secretaria de Atenção à 
Saúde e Secretaria de Ciência, Tecnologia e Insumos Estratégicos, ambas do Ministério da Saúde (BRASIL, 2018).

A partir de 1993, o tratamento intensivo, através de esquema basal-bolus com múltiplas doses de insulina NPH humana e insulina regular humana ou bomba de infusão subcutânea de insulina (BISI) tornou-se o tratamento preconizado para pacientes com DM 1 pois, além do controle dos sintomas de hiperglicemia, este manejo mais intensivo mostrou-se capaz de reduzir o desenvolvimento e a progressão das complicações crônicas micro e macrovasculares da doença em comparação com o tratamento convencional.

E, prossegue quanto ao risco de hipoglicemia em pacientes com DM 1, mesmo submetidos a tratamento terapêutico com insulina NPH e insulina regular:

No entanto, o tratamento intensivo determina maior risco de hipoglicemias, incluindo hipoglicemias graves (definidas como episódio de hipoglicemia onde há a necessidade da intervenção de uma terceira pessoa para resolução do quadro e recuperação do paciente). O risco de hipoglicemias graves pode ser três vezes maior quando em tratamento intensivo em comparação ao tratamento não intensivo, sendo um importante fator limitante à eficácia da terapia insulínica intensiva. O ganho de peso também é complicação decorrente do tratamento intensivo.

Neste contexto, estudos buscaram uma terapia com insulina com menor chance de hipoglicemia. Através de ensaios clínicos, comprovou-se que o uso dos análogos de insulina está associado à menor incidência de hipoglicemias, principalmente as hipoglicemias noturnas (ADA, 2018). Em outras palavras, o uso de análogos de insulina traz um benefício muito importante no desafio dos pacientes de alcançarem níveis glicêmicos ideais, sem hipoglicemias que possam ameaçar a vida dos portadores de DM1.

Há uma subdivisão dos análogos de insulina de acordo com sua duração, os análogos de insulina de longa duração são os que substituem a insulina basal do corpo, já os análogos de curta duração estão relacionados com a alimentação, com intuito de substituir a insulina que seria produzida, em situações normais, nesse momento. (SBD, 2017)

A medicina baseada em evidência se relaciona com a necessidade de estudos científicos, escalona a importância desses estudos, com sua força científica para fornecer um grau de recomendação. Os estudos que estão no topo de evidencias são as revisões sistemáticas e meta-análises. Objetiva, de forma geral, é subsidiar as escolhas clínicas e de políticas públicas baseadas em evidências científicas, e considera a relação de custoefetividade. 
Em revisão sistemática pela The Cochrane Collaboration (apud: SBD, 2011), verificou que, de fato, não se encontrou um grande benefício no alcance das metas com uso dos análogos de insulina ${ }^{3}$, ao invés do uso das insulinas já disponibilizadas pelo SUS. Porém, essa mesma revisão afirma que os análogos de longa duração apresentaram menor incidência de hipoglicemia nos pacientes, especialmente hipoglicemia noturna, e que os análogos de curta duração permitem maior flexibilidade aos portadores da doença e também menor hipoglicemia em determinadas situações.

Ainda no ano de 2010, a ANVISA divulgou trabalho de revisão dos benefícios de alguns análogos de insulina e comprovou eficácia similar entre os análogos de longa duração e a insulina humana NPH, havendo, no entanto, uma maior relevância no uso de análogos de insulina em determinados pacientes com DM 1, como os que apresentam maior frequência de episódios de hipoglicemia noturna (BRASIL, 2011).

O uso da tecnologia análogas a insulina humana em pacientes com DM 1 é particularmente novo, embora já estudado e recomendado, segundo medicina de evidência e estudos mais recentes (ADA, 2018 e SBD, 2017).

A ministração do análogo tem como benefício assegurar ao portador da doença nível glicêmico compatível ao longo do dia, evitando picos de hipoglicemia - considerando que o tratamento tradicional com insulina não garante a manutenção desse nível entre uma aplicação e outra - o que garante ao paciente não somente melhor qualidade de vida com a utilização destas substâncias, como, v.g. a redução de aplicações no decorrer do tratamento, mas, sobretudo, com a redução de comorbidades e complicações associadas ao DM 1, acima ressaltadas.

Enfim, e como será visto adiante, a adoção de análogos de insulina de longa duração tem sido compreendido como ideal e satisfativo à saúde e qualidade de vida aos portadores de DM1.

\section{1 - DIREITO A SAÚde AO PORTADOR DE DIBABETES MELlituS TIPO 1: A ATUAÇÃO DA COMISSÃO NACIONAL DE INCORPORAÇÃO DE TECNOLOGIAS (CONITEC) NO ÂMBITO DO SUS}

\footnotetext{
${ }^{3}$ Os análogos de insulina eram a glargina e detemir.
} 
Como se disse, a Constituição Federal de 1988 ao inaugurar uma nova ordem jurídica, inovou erigindo o direito a saúde como direito fundamental, bem como, criando um sistema único para ações e serviços públicos de saúde, regionalizado, hierarquizado, e com diretrizes voltadas: a descentralização, com direção única em cada esfera de governo; atendimento integral, com prioridade para as atividades preventivas, sem prejuízo dos serviços assistenciais; e participação da comunidade (BRASIL, 1988).

A fim de dar concretude ao direito e ao sistema criado, duas normas foram editadas no início da década de 1990, a Lei no 8.080, de 19 de setembro de 1990, e a Lei no 8142, de 28 de dezembro de 1990, denominadas de Leis Orgânicas o SUS.

Posteriormente, e especificamente ao fornecimento de medicamentos e materiais necessários a aplicação e controle glicêmico capilar aos portadores de diabetes, a Lei $\mathrm{n}^{\circ}$ 11.347, de 27 de setembro de 2006, passou a dispor:

Art. $1^{\circ}$ Os portadores de diabetes receberão, gratuitamente, do Sistema Único de Saúde - SUS, os medicamentos necessários para o tratamento de sua condição e os materiais necessários à sua aplicação e à monitoração da glicemia capilar.

$\S 1^{\circ}$ O Poder Executivo, por meio do Ministério da Saúde, selecionará os medicamentos e materiais de que trata o caput, com vistas a orientar sua aquisição pelos gestores do SUS.

$\S 2^{\circ}$ A seleção a que se refere o $\S 1^{\circ}$ deverá ser revista e republicada anualmente ou sempre que se fizer necessário, para se adequar ao conhecimento científico atualizado e à disponibilidade de novos medicamentos, tecnologias e produtos no mercado.

$\S 3^{\circ}$ É condição para o recebimento dos medicamentos e materiais citados no caput estar inscrito em programa de educação especial para diabéticos.

Ao mesmo tempo em que criou direito subjetivo aos portadores de diabetes em geral para o recebimento, gratuito, pelo SUS, de medicamentos e materiais (insumos), a norma condicionou o fornecimento a prévia seleção de tais medicamentos e insumos por parte do Ministério da Saúde.

Até então, a referida Lei $n^{\circ}$ 8.080/1990, que dispõe sobre as condições para a promoção, proteção e recuperação da saúde, a organização e o funcionamento dos serviços correspondentes e contém outras providências, em sua redação original, apenas incluía no SUS ações de assistência a tratamento terapêutico e farmacêutico (art. 60, I, "d"), sem especificações quanto ao seu funcionamento. 
Contudo, a Lei $\mathrm{n}^{\circ}$ 12.401, de 28 de abril de 2011, ao alterar a Lei $\mathrm{n}^{\mathrm{o}}$ 8.080/1990, passou a dispor sobre a assistência terapêutica e a incorporação de tecnologia em saúde no âmbito do Sistema Único de Saúde - SUS, incluindo assim o capítulo VII - Da assistência terapêutica e da incorporação de tecnologia em saúde, artigos 19-M ao art. 19-U, na Lei no 8.080/1990.

Desde dessa alteração normativa a assistência terapêutica integral, inclusive farmacêutica, no âmbito do SUS, passou a ocorrer com a dispensação de medicamentos e produtos de interesse para a saúde submetida a prescrição em conformidade com as diretrizes terapêuticas definidas em protocolo clínico para a doença ou o agravo à saúde a ser tratado (art. 19-M, I), sendo que, na falta do protocolo, a prescrição passa a ser em conformidade com o disposto no art. 19-P.

Segundo a mesma legislação alterada, a incorporação, a exclusão ou a alteração pelo SUS de novos medicamentos, produtos e procedimentos, bem como a constituição ou a alteração de protocolo clínico ou de diretriz terapêutica, são atribuições do Ministério da Saúde, assessorado pela Comissão Nacional de Incorporação de Tecnologias no SUS CONITEC.

Art. 19-Q. A incorporação, a exclusão ou a alteração pelo SUS de novos medicamentos, produtos e procedimentos, bem como a constituição ou a alteração de protocolo clínico ou de diretriz terapêutica, são atribuições do Ministério da Saúde, assessorado pela Comissão Nacional de Incorporação de Tecnologias no SUS.

A CONITEC, como órgão de assessoramento, e encarregada pela constituição e alteração de protocolo clínicos e diretrizes terapêuticas no âmbito do SUS, deverá levar em consideração, necessariamente para o seu trabalho (1) as evidências científicas sobre a eficácia, a acurácia, a efetividade e a segurança do medicamento, produto ou procedimento objeto do processo, acatadas pelo órgão competente para o registro ou a autorização de uso; e, a (2) a avaliação econômica comparativa dos benefícios e dos custos em relação às tecnologias já incorporadas, inclusive no que se refere aos atendimentos domiciliar, ambulatorial ou hospitalar, quando cabível (art. 19-Q, §2º I e II, da Lei nº 8.080/1990).

Apesar de se constituir como um órgão colegiado de assessoramento do Ministério da Saúde (art. 19-Q, $\S 1^{\circ}$, da Lei $n^{\circ}$ 8.080/1990), o trabalho da CONITEC, é estruturado segundo informam os artigos 19-Q e R; e tem sido fundamental para adoção ou alteração, ao 
fim a cabo das políticas públicas, de "dispensação de medicamentos e produtos de interesse para a saúde" (Art. 19-M, I, da Lei n 8.080/1990).

Define a mesma legislação o que se deve entender protocolo clínico e diretriz terapêutica.

Art. 19-N. Para os efeitos do disposto no art. 19-M, são adotadas as seguintes definições:

I - (...);

II - protocolo clínico e diretriz terapêutica: documento que estabelece critérios para o diagnóstico da doença ou do agravo à saúde; o tratamento preconizado, com os medicamentos e demais produtos apropriados, quando couber; as posologias recomendadas; os mecanismos de controle clínico; e o acompanhamento e a verificação dos resultados terapêuticos, a serem seguidos pelos gestores do SUS.

E prossegue para estabelecer os limites e objetivos dos protocolos clínicos e diretrizes terapêuticas.

Art. 19-O. Os protocolos clínicos e as diretrizes terapêuticas deverão estabelecer os medicamentos ou produtos necessários nas diferentes fases evolutivas da doença ou do agravo à saúde de que tratam, bem como aqueles indicados em casos de perda de eficácia e de surgimento de intolerância ou reação adversa relevante, provocadas pelo medicamento, produto ou procedimento de primeira escolha.

Parágrafo único. Em qualquer caso, os medicamentos ou produtos de que trata o caput deste artigo serão aqueles avaliados quanto à sua eficácia, segurança, efetividade e custo-efetividade para as diferentes fases evolutivas da doença ou do agravo à saúde de que trata o protocolo.

Percebe-se que a legislação reforça que a elaboração do protocolo e diretriz terapêuticas ao estabelecer os medicamentos ou produtos para (1) as diversas fases evolutivas da doença ou do agravo à saúde, (2) e quando da perda de eficácia e em caso do surgimento de intolerância ou reação adversa relevante, devem sempre, "em qualquer caso", levar em consideração, isto é, demonstrar de modo motivado, e segundo as evidências científicas, que a avaliação se deu segundo à sua eficácia, acurácia (segurança), efetividade, e custo-efetivo, conforme, também informa o art. 19-Q, I e II, da mesma norma.

Muito embora a medicina já demonstrasse os benefícios terapêuticos dos análogos de insulina ao portadores de DM1, seja quando dos referidos estudos e revisões da entidade The Cochrane Collaboration, da American Diabetes Association (ADA, 2018), ou, no caso nacional, quando da aludida revisão por parte da ANVISA (2010), e em particular, o Posicionamento Oficial da Sociedade Brasileira de Diabetes (SBD; 2011), o Ministério da 
Saúde, por meio da Secretaria de Ciência, Tecnologia e Insumos Estratégicos, acolheu o Relatório de Recomendação da CONITEC nº 114 (BRASIL, 2014), quando a determinados análogos de insulina, inclusive de longa duração, no sentido de sua não incorporação no âmbito do SUS.

As alegativas para essa não incorporação foram as de que não seria “(...) possível atestar inferioridade, similaridade ou superioridade entre as insulinas análogas de ação longa e rápida em relação aos seus comparadores existentes no SUS” (insulina NPH e regular), “(...) apesar de alguns desfechos parecerem favorecer as insulinas análogas (como menor risco de hipoglicemia noturna)", ponderando, entretanto, pela negativa, haja vista o “(...) elevado custo das insulinas análogas de longa e curta ação, aliado à falta de evidências que demonstrem a superioridade em desfechos clínicos finais (duros)"

Em pedido de reanálise feito pela Secretária Estadual de Saúde de Minas Gerais (SES/MG) ao Ministério da Saúde, a CONITEC expediu novamente recomendação, chamada de Recomendação Preliminar, em dezembro de 2018, a semelhança da anterior, pela não incorporação de insulinas análogas de ação prolongada (glargina, detemir e degludeca) para diabetes mellitus tipo 1 .

Destaque deve ser feito a Portaria ${ }^{\circ}$ 10, de 21 de fevereiro de 2017, da Secretaria de Ciência, Tecnologia e Insumos Estratégicos do Ministério da Saúde, que aprovou o Relatório de Recomendação $\mathrm{n}^{\circ} 245$ para incorporar “(...) insulina análoga de ação rápida para o tratamento da Diabetes Mellitus Tipo 1, mediante negociação de preço e conforme protocolo estabelecido pelo Ministério da Saúde, no âmbito do Sistema Único de Saúde -SUS (BRASIL, 2017). Apesar da Portaria não especificar, a incorporação se limitou a um único tipo específico de análogo de insulina de ação rápida (insulina lispro), conforme pode ser verificado no relatório pertinente.

Mais recente, acolhendo a Recomendação no 440, de março de 2019, da CONITEC, a Secretaria de Ciência, Tecnologia e Insumos Estratégicos incorpora o uso da insulina análoga de ação prolongada para o tratamento de DM 1, ao editar a Portaria $\mathrm{n}^{\circ} 19$, de 27 de março de 2019 (BRASIL, 2019).

Parecia que se estava avançando para a doção de nova tecnologia em saúde no afã de assegurar aos portadores de DM 1 tratamento mais digno, todavia, esta última Portaria condiciona a aquisição do medicamento a questões econômicas. Vejamos. 
Art. $1^{\circ}$ Fica incorporada insulina análoga de ação prolongada para o tratamento de diabetes mellitus tipo I, condicionada ao custo de tratamento igual ou inferior ao da insulina NPH na apresentação de tubete com sistema aplicador e mediante protocolo estabelecido pelo Ministério da Saúde, no âmbito do Sistema Único de Saúde - SUS. (BRASIL, 2019)

Ou seja, a incorporação de uma novidade tecnológica, sabidamente mais eficiente e eficaz a determinados pacientes, foi condicionada ao preço do insulínico já disponibilizados há tempos pelo SUS. O custo do tratamento deverá ser igual ou inferior ao da insulina NPH na apresentação de tubete com sistema aplicador.

Por outro lado, a Portaria $n^{\circ} 19$, de incorporação dos medicamentos análogos a insulina de longa duração para o tratamento de diabetes mellitus tipo I, não deixa de ser um avanço na implementação de maior cobertura, muito embora não se acredite que o valor de um novo fármaco (nova tecnologia) será igual ou inferior ao que já disponibilizado no mercado, e adquirido em longa escalada pelo SUS, o que, na prática, e dada as limitações orçamentárias pode comprometer a efetiva incorporação e melhoria do tratamento aos pacientes necessitados.

Vale destacar que, em data recentíssima, em sessão realizada em 07 e 08 de agosto do corrente ano, a CONITEC recomendou, de modo preliminarmente favorável, a publicação de novo Protocolo Clínico de Diretrizes Terapêuticas para a Diabetes Mellitus Tipo 1, contudo, ainda sujeito à consulta pública e aprovação na instância competente, sendo que agora, diferente do Protocolo vigente (março de 2018), adota de forma expressa o tratamento terapêutico com o uso dos análogos de insulina. No entanto, a incorporação e distribuição dos análogos insulínicos ainda estão sujeitos aos condicionantes da Portaria $\mathrm{n}^{\circ} 19$, de 27 de março de 2019 (BRASIL, 2019).

\section{4 - PRECEDENTES JUDICIAIS PARA O FORNECIMENTO DE MEDICAMENTOS E A DECISÃo DE SUSPENSÃo DE TUTELA PROVISÓRIA No 101 PELO SUPREMO TRIBUNAL FEDERAL}

O fenômeno da crescente judicialização da saúde é recente e acompanha o marco da nova ordem jurídica com a promulgação da Constituição Federal de 1998 (GOUVÊA apud: FERNANDES, 2017, p. 729), sendo que o desafio de se universalizar a saúde como um 
direito e bem público se impõe sobretudo pelo acesso limitado a grande parcela dos nacionais num contexto de pobreza e de um país em desenvolvimento como nosso.

Ao estabelecer o direito à saúde como um dever do Estado, o Poder Judiciário, a contar dessa nova ordem, tem sido chamado a se manifestar, e tido uma postura muitas vezes de autocontenção dado o impacto em definições de políticas públicas, sobretudo quando ao aspecto financeiro que isso envolve; mas, de outro, lado, adotando posturas em reconhecer omissões dos demais Poderes, e proferir decisões para assegurar o direito à saúde.

Neste contexto, no ano de 2000, o Supremo Tribunal Federal em julgamento do RE 271.286, reconheceu o dever do Estado em dar (fornecer) gratuitamente medicamentos a portadores de portadores do vírus HIV, pontuando naquela ocasião que "a interpretação da norma programática não pode transformá-la em promessa constitucional inconsequente" (BRASIL, 2000).

PACIENTE COM HIV/AIDS - PESSOA DESTITUÍDA DE RECURSOS FINANCEIROS - DIREITO À VIDA E À SAÚDE - FORNECIMENTO GRATUITO DE MEDICAMENTOS - DEVER CONSTITUCIONAL DO PODER PÚBLICO (CF, ARTS. 5', CAPUT, E 196) - PRECEDENTES (STF) - RECURSO DE AGRAVO IMPROVIDO. O DIREITO À SAÚDE REPRESENTA CONSEQÜÊNCIA CONSTITUCIONAL INDISSOCIÁVEL DO DIREITO À VIDA. - O direito público subjetivo à saúde representa prerrogativa jurídica indisponível assegurada à generalidade das pessoas pela própria Constituição da República (art. 196). Traduz bem jurídico constitucionalmente tutelado, por cuja integridade deve velar, de maneira responsável, o Poder Público, a quem incumbe formular - e implementar - políticas sociais e econômicas idôneas que visem a garantir, aos cidadãos, inclusive àqueles portadores do vírus HIV, o acesso universal e igualitário à assistência farmacêutica e médico-hospitalar. - $\mathrm{O}$ direito à saúde - além de qualificar-se como direito fundamental que assiste a todas as pessoas - representa consequiência constitucional indissociável do direito à vida. O Poder Público, qualquer que seja a esfera institucional de sua atuação no plano da organização federativa brasileira, não pode mostrar-se indiferente ao problema da saúde da população, sob pena de incidir, ainda que por censurável omissão, em grave comportamento inconstitucional. A INTERPRETAÇÃO DA NORMA PROGRAMÁTICA NÃO PODE TRANSFORMÁ- LA EM PROMESSA CONSTITUCIONAL INCONSEQÜENTE. - O caráter programático da regra inscrita no art. 196 da Carta Política - que tem por destinatários todos os entes políticos que compõem, no plano institucional, a organização federativa do Estado brasileiro - não pode converter-se em promessa constitucional inconseqüente, sob pena de o Poder Público, fraudando justas expectativas nele depositadas pela coletividade, substituir, de maneira ilegítima, o cumprimento de seu impostergável dever, por um gesto irresponsável de infidelidade governamental ao que determina a própria Lei Fundamental do Estado. DISTRIBUIÇÃO GRATUITA DE MEDICAMENTOS A PESSOAS CARENTES. - O reconhecimento judicial da validade jurídica de programas de distribuição gratuita de medicamentos a pessoas carentes, 
inclusive àquelas portadoras do vírus HIV/AIDS, dá efetividade a preceitos fundamentais da Constituição da República (arts. 5º, caput, e 196) e representa, na concreção do seu alcance, um gesto reverente e solidário de apreço à vida e à saúde das pessoas, especialmente daquelas que nada têm e nada possuem, a não ser a consciência de sua própria humanidade e de sua essencial dignidade. Precedentes do STF. (RE 271286 AgR, Relator(a): Min. CELSO DE MELLO, Segunda Turma, julgado em 12/09/2000, ACÓRDÃO ELETRÔNICO DJ 24-11-2000 PP-00101 EMENT VOL02013-07 PP-01409) (sic)

No julgado, o voto do relator destaca que há uma dimensão individual ao direito à saúde “(...) ao reconhecer o direito à saúde como direito público subjetivo assegurado à generalidade das pessoas, que conduz o indivíduo e o Estado a uma relação jurídica obrigacional" (MENDES; BRANCO, 2015).

Outro julgamento, desta feita sob a relatoria do Min. Marco Aurélio, no RE $\mathrm{n}^{\circ}$ 566.471/RN, consolidou-se a tese de que é “(...) dever do Estado de fornecer medicamento de alto custo a portador de doença grave que não possui condições financeiras para comprá-lo" (BRASIL, 2007).

Em data mais recente, no RE 657.718/MG, o STF definiu que não cabe ao Poder Público subsidiar medicamentos experimentais sem registro na ANVISA, excepcionado alguns casos a concessão judicial, uma vez preenchidos determinados condicionantes.

O Plenário, por maioria de votos, fixou a seguinte tese para efeito de aplicação da repercussão geral:

1) O Estado não pode ser obrigado a fornecer medicamentos experimentais.

2) A ausência de registro na Anvisa impede, como regra geral, o fornecimento de medicamento por decisão judicial.

3) É possível, excepcionalmente, a concessão judicial de medicamento sem registro sanitário, em caso de mora irrazoável da Anvisa em apreciar o pedido (prazo superior ao previsto na Lei $\mathrm{n}^{\mathrm{o}}$ 13.411/2016), quando preenchidos três requisitos:

I - a existência de pedido de registro do medicamento no Brasil, salvo no caso de medicamentos órfãos para doenças raras e ultrarraras;

II - a existência de registro do medicamento em renomadas agências de regulação no exterior;

III - a inexistência de substituto terapêutico com registro no Brasil. 4) as ações que demandem o fornecimento de medicamentos sem registro na Anvisa deverão ser necessariamente propostas em face da União. (BRASIL, 2019).

Destaque-se, neste sentido, que, nas análises (recomendações) anteriores a citada Portaria $n^{\circ}$ 19, de 27 de março de 2019, a CONITEC sempre opinou pela não incorporação do tratamento com análogos de insulina a toda a rede pública, pois, em análise custo-efetividade, 
pontuava sempre o alto custo das insulinas de alta duração e a alegada falta de evidências científicas até então, razão da contraindicação à incorporação do fármaco ao sistema de saúde público (BRASIL, 2014).

No tocante ao uso de análogos de inulinas de longa duração, já faz algum tempo que são registrados e comercializados no Brasil, tanto é que o Posicionamento Oficial da Sociedade Brasileira de Diabetes, em sua manifestação datada 2011 (SDB), já possuía como diretriz o uso de alguma delas. Os análogos, portanto, não são considerados como medicamentos experimentais, pois já incorporados no âmbito do tratamento clínico pelos especialistas nacionais, e ao mercado de medicamentos do país.

Também se firmou na jurisprudência do Supremo Tribunal Federal o entendimento de que existe responsabilidade solidária entre os entende da federação quanto ao fornecimento de medicamentos, tendo-se como exemplo a seguinte julgado:

RECURSO EXTRAORDINÁRIO. CONSTITUCIONAL E ADMINISTRATIVO. DIREITO À SAÚDE. TRATAMENTO MÉDICO. RESPONSABILIDADE SOLIDÁRIA DOS ENTES FEDERADOS. REPERCUSSÃO GERAL RECONHECIDA. REAFIRMAÇÃO DE JURISPRUDÊNCIA. O tratamento médico adequado aos necessitados se insere no rol dos deveres do Estado, porquanto responsabilidade solidária dos entes federados. O polo passivo pode ser composto por qualquer um deles, isoladamente, ou conjuntamente. (RE 855178 RG, Relator(a): Min. LUIZ FUX, julgado em 05/03/2015 (BRASIL, 2015).

Considerando tais aspectos, constata-se inúmeras demandas judiciais visando a introdução, no âmbito da rede pública, de tais medicamentos, como exemplos, citamos: a Ação Civil Pública nº 0007010-81.2013.4.02.5001, ajuizada pelo Ministério Público Federal perante a $5^{\text {a }}$ Vara da Seção Judiciária do Estado do Espírito Santo, tendo uma de suas pretensões o fornecimento dos aludidos análogos (em especial a glargina e detemir) para o tratamento de pacientes portadores de DM 1 instáveis ou de difícil controle, isto é, refratários ao uso da insulina já ministrada pela rede básica de saúde; e outra Ação Civil Pública, de $\mathrm{n}^{\circ}$ 24027-56.2012.4.01.3300, aforada também pelo Parquet federal, no âmbito da $1^{\circ}$ Vara da Seção Judiciária do Estado da Bahia. 
Nas aludidas ações não se requeria a implementação de medicamentos considerados experimentais, mas sim de medicamentos incorporados no mercado nacional e, portanto, regulamentos pela ANVISA ${ }^{4}$.

Em relação àquela Ação Civil Pública de $n^{\circ}$ 0007010-81.2013.4.02.5001, houve sentença, confirmada pelo Tribunal Federal Regional da $2^{a}$ Região, ocasião na qual, ao se confirmar a decisão de $1^{\mathrm{a}}$ instância, foi mantido os efeitos s efeitos da tutela antecipada, razão pela qual a Advocacia da União requereu à presidência do Supremo Tribunal Federal, em 03 de abril do corrente ano, a Suspensão de Tutela Provisória ( $\left.n^{\circ} 101\right)$.

O pedido foi no sentido de se suspender a tutela antecipatória que determinou à União Federal a implantação de protocolo clínico para a dispensação de análogos de insulina de longa duração (ação prolongada) para atendimento do paciente com diabetes mellitus tipo 1 na rede pública de saúde; e determinação para que se viabilizasse o custeio e/ou a distribuição, às Secretarias Estaduais de Saúde, dos análogos de insulina de longa duração (glargina e detemir) para o tratamento dos pacientes com diabetes mellitus tipo 1 instável ou de difícil controle, que se enquadrem nos critérios do protocolo clínico a ser elaborado pelo órgão competente vinculado ao Ministério da Saúde, o que restou deferido, em sua maior parte, em sede de decisão liminar, pela presidência do STF.

Contra essa decisão monocrática a Procuradora Geral da República interpôs recurso (agravo regimental), contudo, a decisão restou mantida em seus termos, sobretudo ressaltando-se aspectos relacionados: (1) a questão científica, a (suposta) falta de critérios de evidência; (2) e a questão orçamentária (“(...) risco decorrente da determinação de incorporação de medicamentos (tecnologia, portanto) sem o adequado aporte de recursos à saúde pública").

A situação pende de julgamento, desta feita pelo órgão Plenário do Tribunal, dado o recurso do Ministério Público Federal.

O que chama atenção, contudo, quanto a presente situação, e em particular as decisões proferidas pela presidência do Tribunal - ainda que se saiba que no pedido de Suspensão de Tutela Liminar fulcrado na Lei 8.437, de 30 de junho de 1992, se exerça juízo meramente delibatório, em que se mesclam num mesmo tom a urgência da decisão e a impossibilidade de aprofundamento analítico do caso - é que àquela altura a CONITEC, órgão técnico de

\footnotetext{
${ }^{4}$ O site eletrônico da Agência Nacional de Vigilância sanitária - ANVISA permite consultar os produtos para a saúde, entre os dados, a data de suas autorizações.
} 
assessoramento, do Ministério da Saúde, mais precisamente em dezembro de 2018, quando a questão já estava posta no âmbito do STF expediu Relatório de Recomendação pela não incorporação no SUS de insulinas análogas de ação prolongada (glargina, detemir e degludeca) para diabetes mellitus tipo 1; e, três meses depois, precisamente em 27 de março do presente ano, menos de uma semana antes da última decisão da presidência do Tribunal Superior, datada de 03 de abril de 2019, o Ministério da Saúde, por meio da Portaria $\mathrm{n}^{\circ}, 19$, da Secretaria de Ciência, Tecnologia e Insumos Estratégicos passou a incorporar insulina análoga de ação prolongada para o tratamento de diabetes mellitus tipo I, no âmbito do SUS.

Espera-se que, dado os últimos posicionamentos do Ministério da Saúde, a decisão monocrática seja reformada, ainda que, o mérito da aludida Ação Civil Pública possa estar comprometido em algum aspecto, dada a incorporação dos análogos de insulina de ação prolongada no tratamento terapêutico dos portadores de DM1.

\section{5 - CONCLUSÕES}

O direito à saúde é direito fundamental social, seja em sua dimensão subjetiva ou objetiva, sendo dever do Estado atuar em sua proteção, e desenvolver todas as condições e procedimentos capazes de assegurar o seu gozo, seja em uma concepção individual, seja em perspectiva de uma saúde coletiva, ainda que as escolhas para tanto ocorram consoante a liberdade de escolha do Poder Público, e segundo a reserva do que seja possível.

Após a promulgação da Constituição Federal o Estado ainda que de modo trôpego tem se estruturado, sobretudo no que tange as condições e procedimentos para o efetivo gozo do direito fundamental a saúde, o que se pode ver em termos de normativas, órgãos, procedimentos, na tentativa de se equacionar as limitações econômicas, os avanços da medicina, e a necessidade de um direito que concretize um “(...) estado de completo bem-estar físico, mental e social (...)", segundo o que entende a OMS (1946), o que se observou no direito à saúde dos portadores de diabetes tipo 1.

A limitação orçamentária é uma dimensão a ser sempre considerada, ainda que não se possa conceber uma proteção deficitária, ou retrocessos a direitos e garantias fundamentais, no caso da incorporação de medicamentos e produtos, a legislação atinente ao SUS procura levar em consideração essa dimensão, quando propõe a resolução ada equação "custo- 
efetividade" (art. 19-O, parágrafo único, Lei no 8.080/90), o que é observado nos documentos emitidos pela CONITEC.

De um modo geral, a jurisprudência tem assegurado o direito a saúde, sobretudo, no aspecto aqui analisado quanto a garantia de fornecimento de medicamentos, ainda que com limites, dado aspectos científicos e financeiros (v.g. julgamento do RE 657.718/MG).

De outro lado, tantos outros desafios se impõe, e, sobretudo, dizem respeito ao aumento da judicialização do direito à saúde e a escassez de recursos públicos, o aumento da expectativa de vida da população, o surgimento de novas tecnologias e tratamentos, com a possibilidade de maiores dispêndios, a multiplicação de doenças e novos achados médicoscientíficos, a dificuldade do Poder Público em elaborar políticas públicas condizentes com tal realidade de coisas, combinar suas ações de planejamento e execução, e tomadas de decisões frente as limitações orçamentárias, o que pode ser resumido: nos dilemas e dificuldades quanto a eficácia social dos direitos fundamentais sociais relacionados a saúde.

\section{REFERÊNCIAS}

ALEXY, Robert. Teoria dos direitos fundamentais. Tradução de Virgílio Afonso da Silva. São Paulo: Malheiros, 2015.

AMERICAN DIABETES ASSOCIATION. ADA. Standards of medical care in diabetes. Diabetes Care, 2018.

BARROSO, Luís Roberto. Curso de direito constitucional contemporâneo: os conceitos fundamentais e a construção do novo modelo. São Paulo: Saraiva, 2009.

BRASIL. Constituição (1988). Constituição da República Federativa do Brasil. Brasília: Senado Federal. 1988.

BRASIL. Ministério da Saúde. Secretaria de Ciência, Tecnologia e Insumos Estratégicos. Departamento de Assistência Farmacêutica e Insumos Estratégicos. Relação Nacional de Medicamentos Essenciais: RENAME. Brasília: Ministério da Saúde, 2018.

BRASIL. Lei $\mathbf{n}^{0} 8.080$ de 19 de setembro de 1990. Dispõe sobre as condições para a promoção, proteção e recuperação da saúde, a organização e o funcionamento dos serviços correspondentes e dá outras providências. Brasília: Diário Oficial da União. 20 set. 1990.

BRASIL. Lei $\mathbf{n}^{\circ}$ 12.401, de 28 de abril de 2011. Altera a Lei $\mathrm{n}^{\circ} 8.080$, de 19 de setembro de 1990, para dispor sobre a assistência terapêutica e a incorporação de tecnologia em saúde no âmbito do Sistema Único de Saúde - SUS. Brasília: Diário Oficial da União. 29 abr. 2011. 
BRASIL. Presidência da República. Decreto no 7.646, de 21 de dezembro de 2011. Dispõe sobre a Comissão Nacional de Incorporação de Tecnologias no Sistema Único de Saúde e sobre o processo administrativo para incorporação, exclusão e alteração de tecnologias em saúde pelo Sistema Único de Saúde - SUS, e dá outras providências. Brasília. Dário Oficial da União. 22 dez. 2011.

BRASIL. Ministério da Saúde. Comissão Nacional de Incorporação de Tecnologias no Sistema Único de Saúde. no 359, março de 2018. Protocolo Clínico e Diretrizes Terapêuticas Diabetes Mellitus Tipo 1. Disponível em: http://conitec.gov.br/images/Relatorios/2018/Relatorio_PCDT_DM_2018.pdf. Acessado: 29 jul. 2019.

BRASIL. Ministério da Saúde. Comissão Nacional de Incorporação de Tecnologias. Relatório de Recomendação da CONITEC n⿳ 114. Insulinas análogas para Diabetes Mellitus tipo I. Brasília: 2014. Disponível em: http://conitec.gov.br/images/Relatorios/2014/Insulinas-tipoI-FINAL.pdf. Acessado em: 28 jul. 2019.

BRASIL. Ministério da Saúde. Secretaria de Atenção à Saúde e Secretaria de Ciência, Tecnologia e Insumos Estratégicos. Portaria Conjunta $\mathbf{n}^{\mathbf{0}}$ 08, de 15 de março de 2018, que aprova o Protocolo Clínico e Diretrizes Terapêuticas Diabetes Mellitus Tipo 1, Brasília: 2018. Disponível em: http://conitec.gov.br/images/Artigos_Publicacoes/Portaria-Conjunta-n8_DM 1_retificada_16-07-19.pdf, Acessado em: 28 jul. 2019.

BRASIL. Ministério da Saúde. Comissão Nacional de Incorporação de Tecnologias. Portaria n $^{\circ}$ 19, de 27 de março de 2019. Torna pública a decisão de incorporar insulina análoga de ação prolongada para o tratamento de diabetes mellitus tipo I, no âmbito do Sistema Único de Saúde - SUS. Brasília: Ministério da Saúde, 2019.

BRASIL, Ministério da Saúde. Secretaria de Ciência, Tecnologia e Insumos Estratégicos. Relatório de Recomendação da Comissão Nacional de Incorporação de Tecnologias. Insulinas análogas de ação prolongada para o tratamento de diabetes mellitus tipo I. Brasília: Ministério da Saúde. dez. 2018. Disponível em: http://conitec.gov.br/images/Consultas/Relatorios/2018/Relatorio_InsulinasAnalogas_AcaoPr olongada_DM1_CP81_2018.pdf. Acessado em: 20 ago. 2019

BRASIL, Ministério da Saúde. Secretaria de Ciência, Tecnologia e Insumos Estratégicos. Relatório de Recomendação da Comissão Nacional de Incorporação de Tecnologias para adoção de Protocolo Clínico de Diretrizes Terapêuticas para a Diabetes Mellitus Tipo 1.Brasilia: Ministério da Saúde, mar. 2018. Disponível em: https://www.diabetes.org.br/publico/images/pdf/Relatrio_Diabetes-Mellitus-Tipo-

1_CP_51_2019.pdf. Acessado em: 05 ago. 2019.

BRASIL, Agência Nacional de Vigilância Sanitária. Boletim Brasileiro de Avaliação de Tecnologias em Saúde (BRATS). Ano V, nº 13, dez 2010.

BRASIL. Lei $\mathbf{n}^{\circ} \mathbf{1 1 . 3 4 7}$, de 27 de setembro de 2006. Dispõe sobre a distribuição gratuita de medicamentos e materiais necessários à sua aplicação e à monitoração da glicemia capilar aos 
portadores de diabetes inscritos em programas de educação para diabéticos. Brasília: Diário Oficial da União, 28 set. 2006.

BRASIL. Supremo Tribunal Federal ( $2^{\text {a }}$ Turma). Recuso Extraordinário 271.286. Relator Min. Celso de Mello, 12 de setembro de 2000. Diário de Justiça: Vol. 02013-07, p. 01409, 24 nov. 2000.

BRASIL. Supremo Tribunal Federal. Recurso Extraordinário 566.471/RG, Relator Min. Marco Aurélio, 15 nov. 2007. Diário de Justiça: Viol. 02302-08, p. 01685, 07 dez. 2007.

BRASIL. Supremo Tribunal Federal. Recurso Extraordinário 657.718/MG. Tema 500 da repercussão geral. Redator para o acórdão Min. Roberto Barroso. (pendente de publicação). Disponível em: http://www.stf.jus.br/portal/cms/verNoticiaDetalhe.asp?idConteudo=411857. Acessado em: 31 jul. 2019.

BRASIL. Supremo Tribunal Federal. Recurso Extraordinário 855178/RG, Relator(a): Min. LUIZ FUX, 05 de março de 2015, Diário de Justiça eletrônico: 16 mar. 2015.

BRASIL. Supremo Tribunal Federal. Medida Cautelar na Suspensão de Tutela Provisória 101. Presidente Min. Dias Toffoli, 27 de dezembro de 2018. Diário de Justiça: 20, 04 fev. $2019 . \quad$ Disponível

em:

http://portal.stf.jus.br/processos/downloadPeca.asp?id=15339321474\&ext=.pdf. $\quad$ Acessado em: 05 set. 2019.

BRASIL. Supremo Tribunal Federal. Suspensão de Tutela Provisória 101. Presidente Min. Dias Toffoli, 03 de abril de 2019. Diário de Justiça: 69, 05 abr. 2019. Disponível em: http://portal.stf.jus.br/processos/downloadPeca.asp?id=15339868198\&ext=.pdf. Acessado em: 05set. 2019.

BONAVIDES, Paulo. Direito Constitucional. 34ª ed. atual. São Paulo: Malheiros, 2019.

FERNANDES, Bernardo Gonçalves. Curso de Direito Constitucional. 9a ed. ver. atual. e ampl. Salvador: Juspodivm, 2017.

INTERNATIONAL DIABETES FEDERATION. IDF. Diabetes Atlas, $8^{\text {a }}$ ed. 2017. Disponível em: < http://www.diabetesatlas.org/IDF_Diabetes_Atlas_8e_interactive_EN/ >. Acessado em: 26/03/2018.

MELMED, S; POLONSKY, KS; LARSEN, P. R, KRONENBERG, H. M. Williams Textbook of Endocrinology. 13th edition, 2016.

MENDES, Gilmar Ferreira Mendes. BRANCO, Paulo Gustavo Gonet. Curso de Direito Constitucional. $10^{\circ}$ ed. rev. e atual. SP: Saraiva, 2015.

ORGANIZAÇÃO MUNDIAL DE SAÚDE. Global Report on Diabetes. 2016. Disponível em: http://apps.who.int/iris/bitstream/handle/10665/204871/9789241565257_eng.pdf. Acessado em: 26 mar. 2018. 
ORGANIZAÇÃO MUNDIAL DE SAÚDE. OMS, Constituição da Organização Mundial da Saúde [1946]. Disponível em: http://www.direitoshumanos.usp.br/index.php/OMSOrganiza\%C3\%A7\%C3\%A3o-Mundial-da-Sa\%C3\%BAde/constituicao-da-organizacaomundial-da-saude-omswho.html. Acessado em: 02 set. 2019.

SARLET, Ingo Wolfgang \& TIMM, Luciano Benetti. Direitos Fundamentais: orçamento e "reserva do possível". $2^{\circ}$ ed. rev. e ampl. Porto Alegre: Livraria do Advogado, 2010.

SOUZA NETO, Cláudio Pereira de. SARMENTO, Daniel. Direito constitucional: teoria, história e métodos de trabalho. $2^{\mathrm{a}}$ ed. Belo Horizonte: Fórum, 2016.

SOCIEDADE BRASILEIRA DE CARDIOLOGIA (SBC) E SOCIEDADE BRASILEIRA DE ENDOCRINOLOGIA E METABOLOGIA (SBEM). Arquivo Brasileiro de Cardiologia. v.109, n. 6, 2017.

SOCIEDADE BRASILEIRA DE DIABETES (SBD). Revisão sobre análogos de insulina: indicações e recomendações para a disponibilização pelos serviços públicos de saúde. Posicionamento Oficial Sociedade Brasileira de Diabetes nº 01 [fev. 2011]. Disponível em: https://www.diabetes.org.br/publico/images/pdf/posicionamento-sbd.pdf. Acessado em: 19 de ago. 2019.

VILLAR, L. Endocrinologia Clínica, 6ª edição, São Paulo: Guanabara Koogan, 2016.

VARDI M, Jacobson et al. A and Bitterman H. Intermediate Acting Versus Long Acting Insulin for Type 1 Diabetes Mellitus. Cochrane Database of Systematic Reviews 2008, Issue 3. Art. No.: CD006297, DOI: 10.1002/14651858.CD006297.pub2. 